\title{
Radiological Assessment in Vegetable Crops a Case Study of Benue River Bank Using Nuclear Technique
}

\author{
Anas $\mathrm{MS}^{1^{*}}$ and Yusuf JA ${ }^{2}$ \\ ${ }^{1}$ CAAS Mando, Ahmadu Bello University, Nigeria \\ ${ }^{2}$ Centre for Energy Research and Training, Ahmadu Bello University, Nigeria
}

Submission: February 02, 2017; Published: April 28, 2017

*Corresponding author: Anas MS, CAAS Mando, Division of Agricultural Colleges, Ahmadu Bello University, Nigeria, Tel: +234 8062883863; Email: abuumair399@gmail.com

\begin{abstract}
Quality of four vegetable commonly consumed along Benue river bank at Yola North have been studied using the gross alpha and beta single- channel gas filled detector. The result shows that the average value of Alpha and Beta activity in African Spinach is $8.64 \times 10-5 \pm 3.60 \times 10-$ $5 \mathrm{~Bq} / \mathrm{g}$ and $0.03937 \pm 0.002853 \mathrm{~Bq} / \mathrm{g}$ respectively. Similarly the average value of Alpha and Beta activity obtain in Rosella is $1.015 \times 10$ $4 \pm 3.335 \times 10-5 \mathrm{~Bq} / \mathrm{g}$ and $0.09956 \neg \pm 0.002811 \mathrm{~Bq} / \mathrm{g}$ respectively. The mean value of Alpha activity obtain in Okra is $8.42 \times 10-5 \pm 3.555 \times 10-5 \mathrm{~Bq} / \mathrm{g}$. similarly in the Beta activity is $0.6354 \pm 0.004632 \mathrm{~Bq} / \mathrm{g}$ and similarly the Alpha and beta activity obtain in Lettuce is $1.218 \times 10-4 \pm 4.945 \times 10$ $5 \mathrm{~Bq} / \mathrm{g}$ and $0.3736 \pm 0.003967 \mathrm{~Bq} / \mathrm{g}$ respectively. This research will serve as close monitoring of vegetables contamination by governments and environmentalist even though the Alpha and Beta activities on each Sample are within the recommended values given by W.H.O and ICRP $(12.5 \mathrm{~Bq} / \mathrm{g})$.
\end{abstract}

Keywords: Gross alpha and beta; Radioactivity; Vegetables; Radiation

\section{Introduction}

At earlier part of ' 50 s and at the beginning of ' 60 s pollution by Natural or Artificial radioactivity which is the radioactive nuclides produce due to our unethical behavior and settled down as radioactive fallout which contaminated the entire environment. Radioactive element produce such as $141 \mathrm{Ce}$, "Mo, 133Xe, 140Ba, 140La, 131I, 132I, 133I, 43Pm, 132Te, 90Sr, 137Cs, 106Rh, 144Ce, 95Zr, 90Sr and I37Cs are dangerous even at low levels because the emitted radiations in form of alpha, beta particles and gamma rays can damage in the DNA of cells of vegetables [1].

We are exposed to this Naturally Occurring Radioactive Material (NORM) and artificial radioactive element through air, food, soil and water within our environment. Monitoring radioactive material are therefore of primary importance for human and environmental protection. The radiation from radionuclide can cause damage to living tissues only when the energy is absorbed in that tissues and one of the major pathways through which it passes to people is food [2].

The extent of the harm caused to cells by radiation depends on the nature of the rays, the part of the body exposed to radiation and the dose received [3]. Alpha particles are absorbed in the dead surface of the skin and are therefore not dangerous. If the source however is taken into the body through food, water or dust, then alpha particles can cause great damage. Beta particles cannot be stopped by a sheet of paper. Some beta particles can be stopped by human skin, but some need a thicker shield (like wood) to stop them. Just like alpha particles, beta particles can also cause serious damage to your health if they are inhaled or swallowed. Even some materials that emit beta particles might be absorbed into your bones and caused damage if ingested [4].

Vegetables consist of a large group of plant consumed as food. They are excellent sources of certain minerals and vitamins and are often the main source of dietary fibres. The consumption of vegetables has increased significantly as consumers have becomes more health conscious. There are in numerable benefits of consuming green leafy vegetables. There include a whole lot of vitamins that are required to remain fit and also to prevent some diseases and health problems. Dark green vegetables contain not only vitamins $\mathrm{A}, \mathrm{D}, \mathrm{E}$ and $\mathrm{K}$, but are also rich in fibre which aids in cleansing the digestive tract. They also contain potassium, iron, magnesium, calcium, folic acid and certain photo-chemicals that are important for the proper functioning of the body. Vegetables are vital in our diet and the presence of natural radionuclide in them has certain radiological implication not only in the food but also on the entire populace consuming there vegetable [5].

The world is highly demand power sources which lead to the use of radionuclide (Radioactive elements) such as $238 \mathrm{U}$ and 
232Th to generate energy, Application in medicine for Diagnosis, Oil and Gas extraction and production of Naturally Occurring Radioactive Materials (NORM) contribute to the increase in the percentage of radioactive level on vegetable in our environment which may lead to the human hazard or diseases due to dumping of refuse along the river banks as shown in the picture above which is the study area [6].

The area is situated approximately between latitudes $9012^{\prime} 0$ $\mathrm{N}$ and $12029^{\prime} 0 \mathrm{E}$ of the Northern Yola (Jimeta), Adamawa State of Nigeria. The Benue River is the chief tributary of Niger River and flows across $1402 \mathrm{~km}$ through northwestern sub-Saharan Africa chiefly northern Cameroon and eastern Nigeria, Prior to discharging to the Niger River near the central Nigerian city of Lokoja as shown in Figure 1-3.

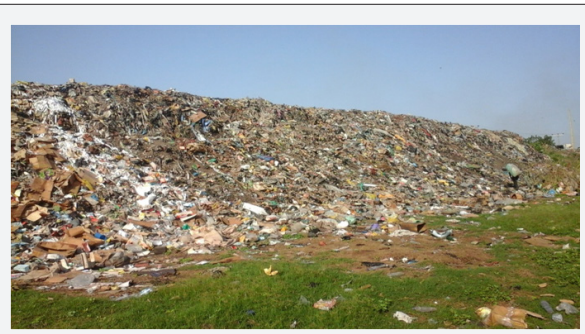

Figure 1: The dumpsites along Benue River at Yola town.

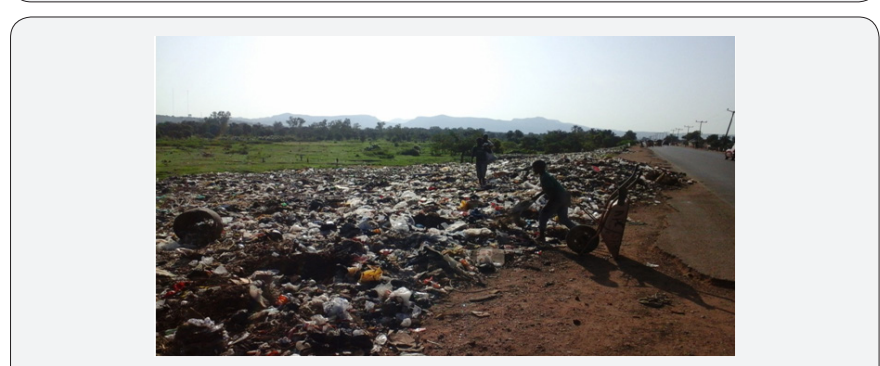

Figure 2: The dumpsites and pollution produce along Benue River at Yola town.

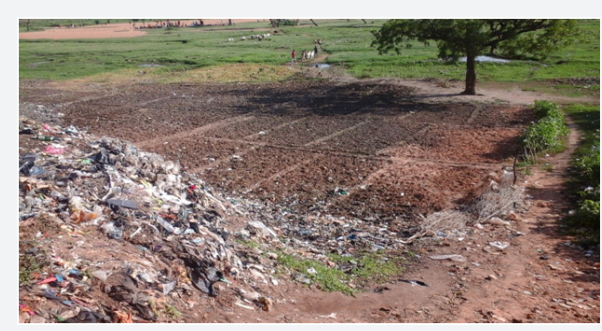

Figure 3: The dumpsites and farming activities along Benue River at Yola town.

In order to measure the degree of contamination of radionuclide in vegetables; the gross alpha and beta activity are measured.

\section{Materials and Methods}

\section{Experimental method}

Four irrigation places were visited along the river and they are: Bajabure, Vonuklang, Doubeli, and Geriyo with verities of vegetable as follow: Spinaciaoleracea (African Spinach), Roselle, Pistia stratiotes (Lettuce), and Esculentus (Okoro).

The stratified random sampling was used as recommended by Williams, 1997 and a little reasonable quantity of the vegetable samples was carefully uprooted. Soil sample surrounding each plant, which covers $20 \mathrm{~cm} \times 30 \mathrm{~cm}$ were also collected. Due to tap root system the soil was dug up to $15 \mathrm{~cm}-30 \mathrm{~cm}$ down using hand trowels. A reasonable quantity of the soil sample was transferred into a very clean polythene bag separately after mixing up each one of them thoroughly. Afterwards, the samples were transported into the laboratory at the Centre for Energy Research and Training Ahmadu Bello University Zaria (CERT, ABU ZARIA) were the sample are dried, grinded and pelletized. After that, taking it to laboratory of the analysis then to the counting room. The equipment is automated. The procedure involves entering the pre-set time, number of cycles and counting mode. The results were displayed as raw counts, count rate (Cpm). The data were required for alpha only mode and alpha count rate. The raw counts (Cpm) were repeated three times each for all the samples and the average value was obtained respectively. The alpha activities were calculated using the formula:

Activity $(\mathrm{Bq} / \mathrm{g})=($ Net count $(\mathrm{CPM})) /(\mathrm{DE} \times 60 \times$ Pellet Weight)

Where DE is the detector's efficiency and net counts is given by:

Net counts $=$ raw counts $(\mathrm{Cpm})-$ background $(\mathrm{Cpm})$

As it was stated above, DE simply represents detectors efficiency. This efficiency is determined by measuring samples of known activity (calibrated sources) under similar conditions. That's why it's very important to have the detection system properly calibrated. The uncertainty (Error) of measurement is calculated with the formula:

$\mathrm{UN}(\mathrm{Bq} / \mathrm{g})=\sqrt{\left(\mathrm{COUNT} /(\mathrm{CT})^{\wedge} 2\right.}+\mathrm{BKG} /\left[(\mathrm{CT}) \rrbracket^{\wedge} 2\right) /$
$(\mathrm{DE} \times 60 \times \mathrm{PELLET}$ WEIGHT $)$

The final result should be expressed as Activity $( \pm$ uncertainty), in Becquerel. (Bq).

\section{Results and Discussion}

The results obtained are presented in Table 1 and the diagrams representing the level of radio activities on each sample are shown in Figure 4.

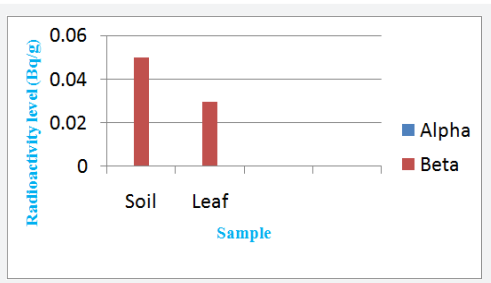

Figure 4: Bar chart representing values of activities in African spinach. 
In research the radionuclide of the environment attention focus on the issue of vegetable and soil contamination. The existence of radionuclides in the soil sample and their possible transfer to vegetable is a significant problem. The transfer factor depends not only on the type of plant but also on the binding mechanism of the isotope by the soil system [1]. These studies also have practical aspects, as they allow us to find places of isotope accumulation and evaluate the possibility of the isotope transfer into the food chain.

Obtained results of alpha and beta activities are presented in Figure 4-7.

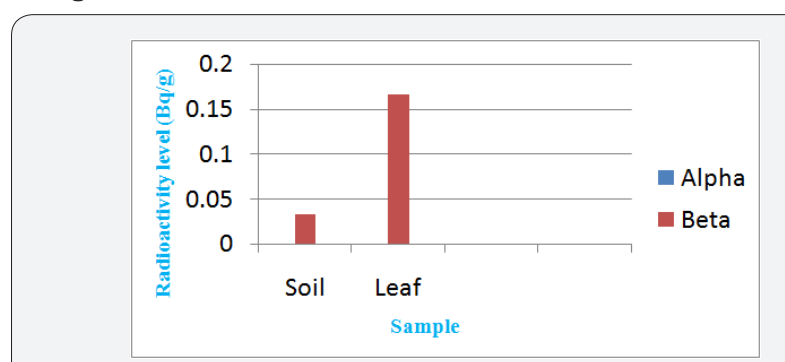

Figure 5: Bar chart representing values of activities in Rosella.

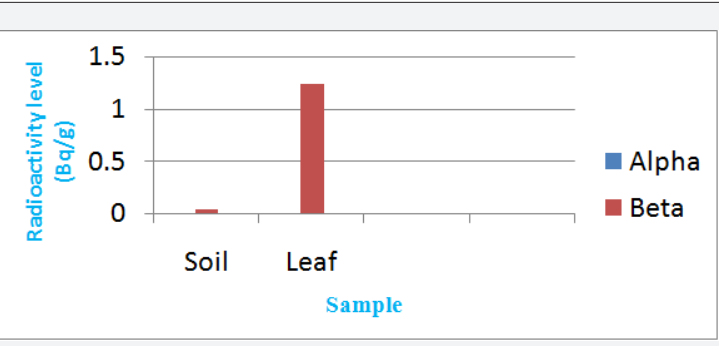

Figure 6: : Bar chart representing values of activities in Okra.

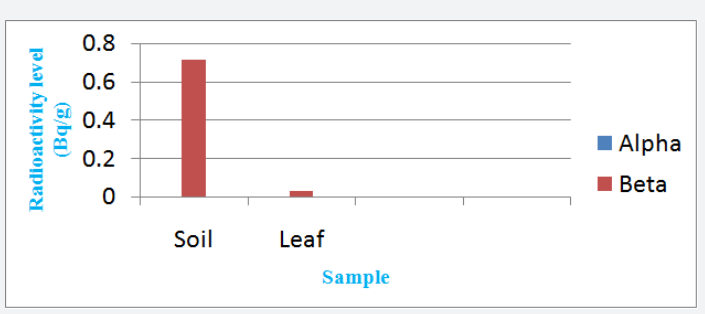

Figure 7:Bar chart representing values of activities in Lettuce.

Table 1 shows that the measurement could be from one of the following major sources, anthropogenic factor (i.e. the atmospheric fall out).

From the result presented in the Table 1 shows that the mean value of Alpha activity obtain in African Spinach is $8.64 \times 10-5 \pm 3.60 \times 10-5 \mathrm{~Bq} / \mathrm{g}$. Similarly in the Beta activity is $0.03937 \pm 0.002853 \mathrm{~Bq} / \mathrm{g}$. while the mean value of Alpha activity obtain in Rosella is $1.015 \times 10-4 \pm 3.335 \times 10-5 B q / g$. Similarly in the Beta activity is $0.09956 \neg \pm 0.002811 \mathrm{~Bq} / \mathrm{g}$. The mean value of Alpha activity obtain in Okra is $8.42 \times 10-5 \pm 3.555 \times 10$ $5 \mathrm{~Bq} / \mathrm{g}$. similarly in the Beta activity is $0.6354 \pm 0.004632$ $\mathrm{Bq} / \mathrm{g}$ and the mean value of Alpha activity obtain in Lettuce is
$1.218 \times 10-4 \pm 4.945 \times 10-5 \mathrm{~Bq} / \mathrm{g}$. Similarly in the Beta activity is $0.3736 \pm 0.003967 \mathrm{~Bq} / \mathrm{g}$. This means the Beta activities on each Sample are higher than that of Alpha activity but doesn't exceed the recommendation values given by W.H.O and ICRP $(12.5 \mathrm{~Bq} / \mathrm{g})$.

Table 1: Alpha and Beta Radio Activities Present in Samples.

\begin{tabular}{|c|c|c|c|}
\hline \multirow{2}{*}{ S.No. } & Samples & $\begin{array}{c}\text { Alpha Activities } \\
\text { Bq/G }\end{array}$ & $\begin{array}{c}\text { Beta Activities } \\
\text { Bq/G }\end{array}$ \\
\hline \multirow{3}{*}{1} & \multicolumn{3}{|c|}{ African Spinach } \\
\cline { 2 - 4 } & Soil land & $1.32 \times 10_{-4} \pm 4.49 \times 10^{-5}$ & $0.04992 \pm 0.002802$ \\
\cline { 2 - 4 } & Leaf & $4.08 \times 10_{-5} \pm 2.87 \times 10-5$ & $0.02953 \pm 0.002904$ \\
\hline \multirow{3}{*}{2} & \multicolumn{3}{|c|}{ Rosella } \\
\cline { 2 - 4 } & Soil land & $1.82 \times 10^{-4} \pm 4.34 \times 10^{-5}$ & $0.03251 \pm 0.00197$ \\
\cline { 2 - 4 } & Leaf & $2.1 \times 10^{-5} \pm 2.33 \times 10^{-5}$ & $0.1666 \pm 0.003652$ \\
\hline \multirow{3}{*}{3} & \multicolumn{3}{|c|}{ Okra } \\
\cline { 2 - 4 } & Soil land & $1.13 \times 10^{-4} \pm 3.84 \times 10^{-5}$ & $0.03820 \pm 0.002373$ \\
\cline { 2 - 4 } & Leaf & $5.54 \times 10^{-5} \pm 3.27 \times 10^{-5}$ & $1.2326 \pm 0.00689$ \\
\hline \multirow{3}{*}{4} & \multicolumn{3}{|c|}{ Lettuce } \\
\cline { 2 - 4 } & Soil land & $2.33 \times 10^{-4} \pm 5.56 \times 10^{-5}$ & $0.7161 \pm 0.004919$ \\
\cline { 2 - 4 } & Leaf & $1.06 \times 10^{-4} \pm 4.33 \times 10^{-5}$ & $0.03103 \pm 0.003014$ \\
\hline
\end{tabular}

The alpha and beta activities measured in the African spinach and Lettuce, the leaf is lower than that of the soil. This is expected because the root absorbed nutrients from the soil through a process known as osmosis and translocated those nutrients which may contain radionuclides into various parts of the plant where needed which can be as a result of refuses that were dump along the river bank. While in the concentration of alpha measured in Rosella and Okra, the leaf is lower than that of the soil but the concentration of beta measured in Rosella and Okra however, increases from the soil region to the leaf. These results of course, indicate that primordial factor can be responsible for the abnormal trend. Radioactive material falling from the air or carried in rain water or snow, can deposit on the surface of foods like fruits and vegetables. The surface area of Rosella and the body of Okra are broad compare to that of African spinach and Lettuce [7-12].

The presents the radioisotopes of the element that can be responsible of the emitting of alpha and beta are chromium, vanadium, copper, manganese and zinc in small proportion, these elements are minute in quantity compared to the IAEA's standard limit values for trace/heavy metal's concentration. Hence the form land is suitable and safe for agricultural and the results can serve as a data base line for government and environmentalist.

\section{Conclusion}

The method of gross alpha and beta spectrometry has been used to determine the radioactivity concentrations of four vegetable samples commonly consumed along Benue River in yola northern Nigeria. The gross alpha and beta spectrometry analysis of these vegetables (African spinach, Lettuce, Rosella and Okra) shows that the activity concentrations measured are 
below the recommended activity concentration in food sample by the ICRP $(12.5 \mathrm{~Bq} / \mathrm{g}$ ) and (UNSCEAR 2000) by $2.4 \mathrm{mSvy}-$ 1. Hence, the safety limits implies that the vegetables pose no threat to people consuming it. Hence the hygienic status soil is safe for agricultural purposes.

\section{References}

1. Chibowski S (2000) Studies of Radioactive Contaminations and Heavy Metal Contents in Vegetables and Fruit from Lublin, Poland. Polish Journal of Environmental Studies 9(4): 249-253.

2. FAO (2003) FAO/IAEA programme of Nuclear Techniques in food and Agriculture held in Chania.

3. Gabriel (2007) New findings on the effects of radiation on human should be given greater consideration. Federal ministry of the Environment, Berlin.

4. Carini F (2001) Radionuclide transfer from soil to fruit. J Environ Radioact 52(2-3): 2.

5. Fortunati P, Brambilla M, Sperooni F, Carini F (2004) Foliar uptake of Cs-134 and Sr-85 in strawberry as function by leafage. J Environ Radioact 71: 187-199.
6. Rigol V, Rauret (2002) Journal of environmental radioactivity 58(2-3): 191- 216.

7. Akpa TC, Mallam SP, EandOnoja RA (2004) Characterization of Gross Alpha and Beta Proportional Counter. Nigeria Journal of Physics 16(1): 13-18.

8. King C (2010) ICRP: International Commission on Radiological Protection (2003). Public health.

9. www.buzzle.com

10. Tschiersch J, Shinonaga T, Hauberger H (2009) Dry deposition of gaseous radionuclides and particulate radio-caesium onto leafy Vegetables. Sci Total Environ 407(21): 5685-5693.

11. WHO (2003) Radiological quality of drinking water. World Health Organization, Geneva, Switzerland, p. 18.

12. Williams GC (1997) Sampling Techniques. ( $3^{\text {rd }}$ edn), New York, USA, pp. 89-92.

\section{Your next submission with Juniper Publishers} will reach you the below assets

- Quality Editorial service

- Swift Peer Review

- Reprints availability

- E-prints Service

- Manuscript Podcast for convenient understanding

- Global attainment for your research

- Manuscript accessibility in different formats

( Pdf, E-pub, Full Text, Audio)

- Unceasing customer service

Track the below URL for one-step submission https://juniperpublishers.com/online-submission.php 